\title{
PSYCHOLINGUISTIC FEATURES OF IMAGINATION AS A COMPONENT OF LUDIC COMPETENCE
}

\author{
Iuliia Kobzieva ${ }^{1}$ \\ yu.kobzeva88@gmail.com \\ Iia Gordiienko-Mytrofanova ${ }^{1}$ \\ ikavgm@gmail.com \\ Serhii Sauta ${ }^{2}$ \\ sergeisauta@gmail.com \\ ${ }^{1}$ Department of psychology \\ ${ }^{2}$ H. S. Skovoroda Kharkiv National Pedagogical University \\ 29 Alchevskikh str., Kharkiv, Ukraine, 61002
}

\begin{abstract}
Ludic competence is an integral part of the professional competence of would-be psychologists; the psycholinguistic features of imagination are in turn an integral component of the ludic competence. We used the method of applied psycholinguistic research in order to define and explain the psycholinguistic features of imagination as a component of the ludic competence. The main stage of the research was a free association test with the stimulus word "imagination", as the most elaborated technique of semantic analysis. The psycholinguistic features of imagination as a notion that belongs to the inner world and as a component of the ludic competence were reflected in everyday linguistic consciousness as three core (more than $10 \%$ ) semantic clusters:

a) associates that reflect psychological processes and states $(54.5 \%)$;

b) associates that are connected with creative activity (25.5\%);

c) associates that describe the outside world (11\%).

Imagination was mostly represented by lexemes with abstract semantics. The semantic content of the word "imagination" did not depend on gender identification. Both male and female respondents showed a positive emotional attitude to the stimulus "imagination" and evaluated it as something positive. Our data confirm that the psycholinguistic experiment and the method of free association, in particular, can be extensively applied beyond linguistics and prove to be rather effective.
\end{abstract}

Keywords: playfulness, ludic competence, imagination, psycholinguistic experiment, free association test.

DOI: $10.21303 / 2504-5571.2020 .001128$

\section{Introduction}

The present article continues a series of articles, devoted to playfulness as a stable personality trait $[1,2]$. A keen interest in playfulness as a personal characteristic can be explained by the fact that playfulness underlies ludic competence which is an integral part of the professional competence of would-be psychologists.

We define the ludic competence as a system of inner resources, to which a person turns in order to balance their personality against external conditions of the social environment on the basis of positive emotions, e. g., interest and joy, which are frequently expressed in a very emotional way and accompanied by tension or excitement. The ludic competence is formed alongside with the development of playfulness, which is a stable personality trait in the modern world of gamification. Playfulness manifests itself in how a person creatively adapts to the reality of their own "Self" (individual identity) and to the reality of the World (social identity), accepting this task as an exciting challenge.

In Ukraine, we are among the few researchers, studying playfulness [3] with the help of psycholinguistic methods and psycholinguistic experiments in particular, the main stage of which is free association test. Understanding the nature of playfulness with the help of psycholinguistic experiments reconstructs its essential characteristics as semantic components that are actualised in the linguistic consciousness of native speakers, "as a unity of all its constituent semantic components that vary in intensity and can be either core or peripheral" [4, p. 99]. 
Previously, we carried out the most extensive longitudinal free association test with the stimulus word "playfulness" (4,795 respondents). In order to explore common tendencies and characteristic features of the general population (which is the whole population of Ukraine aged 18-75 who are fluent in Russian) and meet the objectives of this research, several samples were formed. The way we formed our sample groups quantitatively and qualitatively was theoretically and experimentally explained in our previous study [5]. The sufficient size of the experimental sample varies from 400 to 1,500 people depending on the qualitative and quantitative features of general population and research conditions. One of the main strategies of sample formation is to single out strata, followed by randomisation. In other words, we divide the general population into strata, i. e. groups that share certain parameters (gender, age, status, education, etc.) and apply randomisation.

Nineteen psycholinguistic meanings of playfulness were described as a result of the psycholinguistic experiment with a sample of 1,600 respondents [3]. Based on the previous theoretical and empirical research into playfulness as a personality trait $[6,7]$, as well as the analysis of the components/scales of playfulness [8,9], high-frequency reactions of the biggest sample of 4,795 respondents, and established psycholinguistic meanings, we managed to single out the following components of playfulness: "sensitivity", "sense of humour", "ease”, "imagination", "flirting", "impishness", "fugue" [10, 11]. The components of playfulness as an integral personality trait are also the components of the ludic competence.

Being mentioned above, imagination is one of the components of the ludic competence. In our ludic competence coaching sessions, we followed S. L. Rubinstein and considered imagination as the essential manifestation of a personality in terms of typology and individual differentiation. It is imagination that allows a person to perceive a difficult situation as an initial benchmark and material that has to be transformed, rather than an invariable fact [12, p. 367].

Scholars who have explored playfulness as a personality trait have also linked playfulness and imagination. For example, R. Proyer [13], who studies playfulness from the psycholinguistic approach, analysed the hierarchical structure of playfulness that enabled him to single out seven factors:

a) cheerful/engaged;

b) whimsical;

c) impulsive;

d) intellectual-charming;

e) imaginative;

f) light-hearted;

g) kind/loving.

We know of only one questionnaire, dealing with playfulness, in which imagination was one of the scales of playfulness. This is the Five-Factor Personality Questionnaire (FFPQ), developed by Heijiro Tsuji and his colleagues [8]. The "playfulness" factor consists of the following facets: curiosity, fantasy, sentiment, sensitivity to internal experience, and fugue.

The aim of the present paper is to use the method of applied psycholinguistic research to define and explain the psycholinguistic features of imagination as a component of the ludic competence. The following objectives were outlined: to determine the key notions that reflect the psycholinguistic features of imagination; to define the general and specific features of the verbal behaviour of young respondents in the framework of studying the stimulus word "imagination"; to suggest major strategies and methods of defining the psycholinguistic features of imagination.

First, let us define the basic notions that are related to the psycholinguistic experiment: "verbal behaviour" and "linguistic consciousness".

Verbal behaviour refers to a behaviour that includes verbal reactions, such as speaking, reacting to words, remembering a verbal material, etc. In the framework of our research, verbal behaviour is applied in a rather limited way, i.e. as written reactions to the stimulus words. In this context, the term "verbal behaviour" is synonymous to the term "associative behaviour".

Linguistic consciousness is coined as "the aggregate of psychological mechanisms of speech generation and understanding, as well as retaining the language in consciousness, i. e., 
mental mechanisms that underlie a person's speech activity" [14, p. 32]. It should be noted, that this approach describes linguistic consciousness from the perspective of psycholinguistics, science with the human linguistic consciousness in the context of its psychological reality as an exclusive object of the study [4].

The associative field, obtained in the course of the association experiment is "not only a fragment of the verbal memory of a human being, but also a fragment of the image of the world, shared by a particular ethnos, reflected in the consciousness of an average representative of some particular culture, their motives and judgments, and, consequently, cultural stereotypes" $[15$, p. 98]. The scope and nature of reactions in associative fields tell us a lot about the word usage, revealing the content of the word, which is psychologically common among the native speakers of the language.

\section{Methods}

The research was conducted during 2016-2018. The total number of respondents was 200 young people (age 21-30), males and females equally represented. By education, $55 \%$ were university graduates, $44.5 \%$ undergraduates, and $0.5 \%$ vocational trainees. By marital status, $19.5 \%$ were married, $80.5 \%$ were single, and $0.5 \%$ were divorced.

Here we consider it expedient to explain our choice of age group. The systematic study into the intellectual functions of adults aged 18-35 that was conducted under the guidance of B. G. Ananiev showed that the most considerable changes occur in the short-term verbal memory and deal with visual and auditory modalities. The highest rate of development occurs between the ages of 18 and 30, which is followed by a slight decline. The figurative memory is subjected to fewer changes with age, and the verbal impressions of the long-term memory are characterized by a high continuity of indicators at the age of 18-35 [16].

The authors ensure that the study has been carried out in accordance with The Code of Ethics of the World Medical Association (Declaration of Helsinki) for experiments, involving humans; approved by the local institutional review board (protocol No.12 of the Department of Psychology of H.S. Skovoroda Kharkiv National Pedagogical University, 23.05.2018). Written informed consent was obtained from all participants.

The main method of this research is experimental: a psycholinguistic experiment whose main goal is to single out the psycholinguistic features of imagination as a component of the ludic competence. The main stage of the research was a free association test with the stimulus word "imagination" as the most elaborated technique of semantic analysis.

As additional methods, we used surveys (to refine the results of the free association test) and questionnaires (to specify the characteristics of the sample). As a mathematical-statistical method to analyse the results of the research, we used frequency and cluster analysis, which allowed us to identify tendencies in the distribution of associations, expressed by the experimental group. The free association test with the stimulus word "imagination" was conducted in written form. Respondents were instructed to state their gender, age, education/specialization, occupation/position, marital status, and write down the first five words that came to their minds that were somehow associated with "imagination".

\section{Results}

\section{1. Building associative fields by five reactions and by the first reaction}

The frequency analysis of the free association test with the stimulus word "imagination" enabled us to build associative fields by five reactions and by the first reaction. A total of 929 reactions were expressed by the respondents (the results of the free association test by five reactions). Out of these, 380 reactions were unique (reactions, expressed with different lexemes [17]), including 24 word combinations or complete sentences; 118 reactions with a frequency greater than one; 262 isolated cases (reactions with a frequency that equals one [17]); and 0 declined to answer the question.

As far as the first reaction is concerned, the free association test with the stimulus word "imagination" yielded 200 associations, of which 100 were unique, including 4 word combina- 
tions or complete sentences; 26 reactions with a frequency greater than one; 74 isolated cases; and 0 declined to answer the question.

The comparative analysis of the associative fields (by the first and by five additional reactions) prompted the conclusion that the composition and nature of the reactions have not changed significantly (Fig. 1).

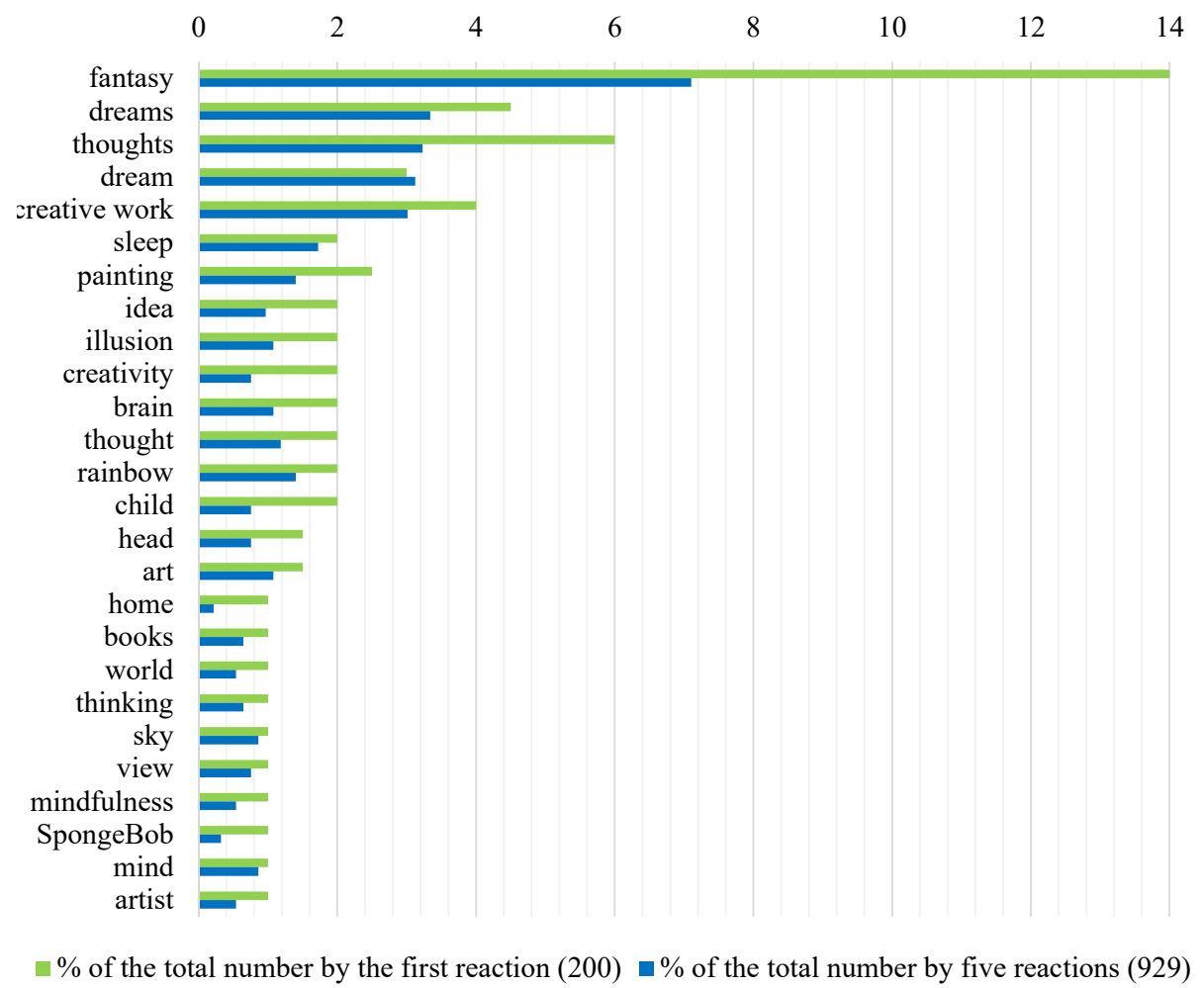

Fig. 1. Comparative analysis of the associative fields by the first reaction and by five additional reactions to the stimulus word "imagination"

What has changed, though, is the sequence of reactions, as well as the quantity of peripheral reactions and isolated cases. The latter can be easily explained, as the increase in the number of respondents causes an increase in the number of isolated cases that reflect individual meanings, generated by the respondents.

Among the most vivid and interesting peripheral reactions were the following: "goal" (7 (0.75 \%)), "subconsciousness" (5 (0.54 \%)), "mirage", (4 (0.43\%)), “development", "meaning" (3 (0.32 \%)), "space", "memory", "freedom", "consciousness", "miracles" (2 (0.22\%)); the first figure in parentheses shows the number of reactions, and the second its percentage.

3. 2. Partial semic interpretation of the results of the frequency analysis of the free association test with the stimulus word "imagination" by the first reaction

The partial semic interpretation of associative reactions involves combining cognate words and nominations of the same semantic component, expressed by different parts of speech, and also singular and plural forms of the same word. The partial semic interpretation allows us to obtain more objective data on (a) high-frequency associates ('associate' is a speech response to a stimulus, usually lexical), and (b) the quantity of different sememes that were revealed during the experiment. For example, clouds 2 [clouds -1 , small cloud -1]. The analysis of the data from the partial semic interpretation resulted in a changed sequence of some high-frequency associates in comparison with the reactions. However, the composition and the nature of the associations remained the same. 


\section{3. Determining general and specific features of the verbal behaviour of the young} respondents

The general features of the verbal behaviour of the young respondents are represented in the following lexemes (used by both males and females): "fantasy" (31 (15.5\%), "thoughts" (19 (9.5\%)), "dreams" (16 (8\%)), "paintings" (6 (3\%), "brain", "creativity", "idea", "illusion", "mind" (4 (2\%)), "view" (3 (1.5\%)), "artist", “books", "sky", “something made up", "sketch", "SpongeBob" (2 (1 \%)).

In order to find gender-specific features of the verbal behaviour of the young respondents, "male" and "female" associative fields were built with the stimulus word "imagination". The criterion for defining the specific features that are characteristic of female/ male respondents and are reflected in certain lexemes was the absence of certain lexemes in the "male"/ "female" associative field.

For instance, female-specific features manifested themselves in such lexemes as "creative work" (8\%/0\%), "child", "rainbow" (4\%/0\%), "abstraction", "clouds", "colour" (2\%/0\%); the figure after the slash refers to the frequency of these reactions among male respondents.

Male-specific features manifested themselves in such lexemes as "sleep" (4\%/0\%), "art", "head" (3\%/0\%), "house", "peace/world" (the Russian word мup means both "peace" and "world" - ed.) $(2 \% / 0 \%)$; the figure after the slash refers to the frequency of these reactions among female respondents (Fig. 2).

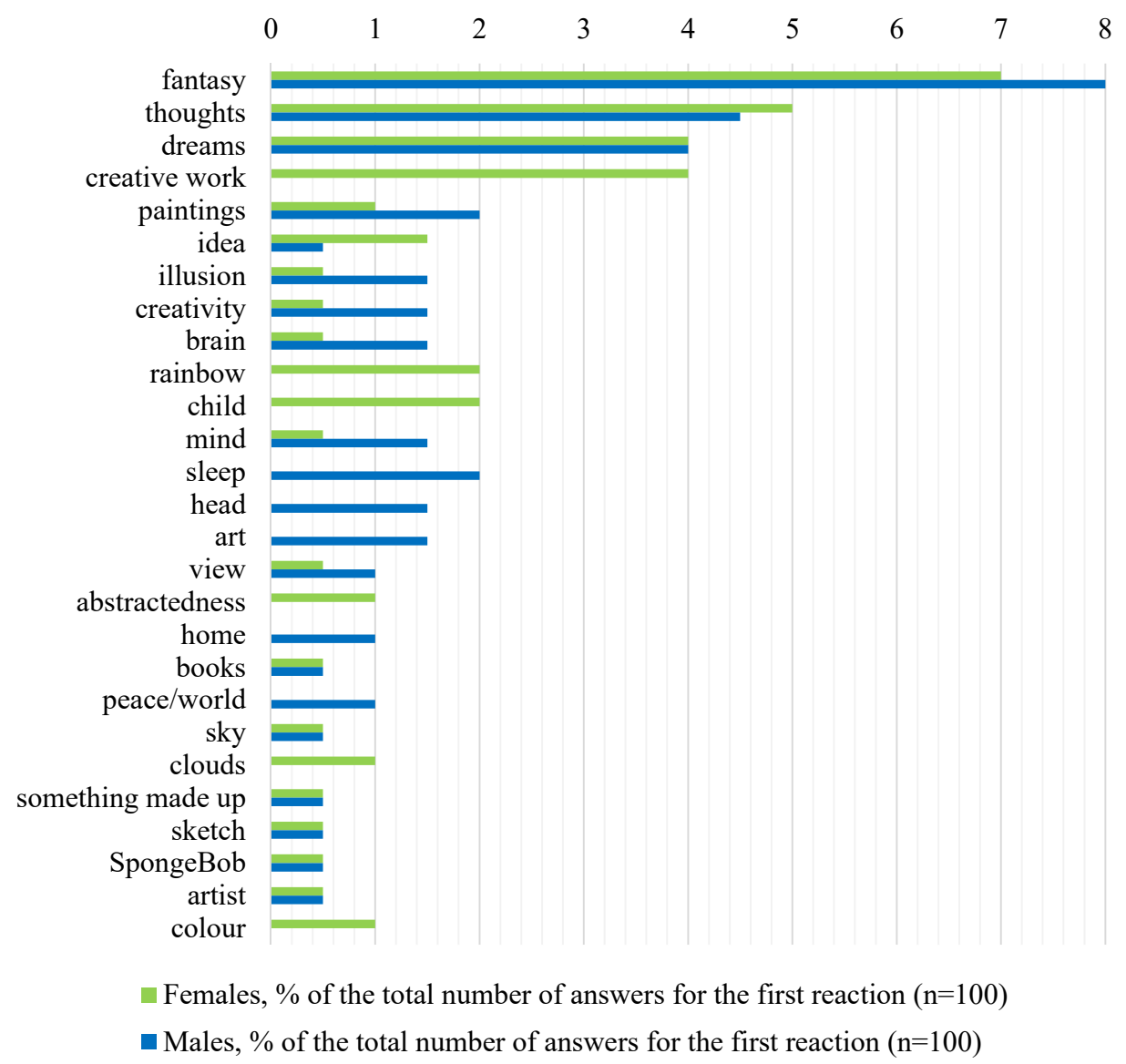

Fig. 2. Comparative analysis of associations of male and female samples to the stimulus "imagination"

The associations from the extreme periphery are mainly actualised by such semes of imagination as "results of creative work" and "outside world". Among the individual male reactions to the stimulus "imagination", there was one reaction with a negative connotation - "lechery". 
Nevertheless, the young respondents generally showed a positive emotional attitude to the stimulus "imagination" and evaluated it as something positive. It should be mentioned here, that the sample did not yield any professionally determined reactions.

\section{4. Semantic clusters}

The reactions were distributed among various clusters on the basis of the algorithm of describing psycholinguistic meanings, developed by I. A. Sternin [13]. As a result of the research, 200 reactions were distributed among the following semantic groups/clusters:

1) Associates that describe psychological processes and states: 109 (54.5\%), f. 48 (24\%), m. 61 (30.5\%); m., f. - the frequency of male and female reactions; the first figure means the frequency, and the figure in parentheses shows the proportion of this reaction in the associative field. This cluster includes semantic groups 1.1-1.3:

1. 1. Associates that reflect the forms of fantasies and their qualitative characteristics: fantasy 31 [fantasy 29, fantasies 1, fantasizer 1], dreams 16 [dreams 9, dream 6, daydreaming 1], illusion 4, sleep 4, infinity 1 , raving 1 , future 1 , inner world 1, opportunities 1 , desire 1 , view 2 , visualise 1, something incredible 1, brilliance $1-66(33 \%)$, f. $29(14.5 \%)$, m. 37 (18.5\%); the numbers show the summarised frequencies of reactions.

1. 2. Associates that reflect psychological processes: thinking, perception, feeling: thoughts 19 [thoughts 12 , thought 4 , thinker 1, thinking 2], idea 4, brain 4, mind 2, reason 2 , head 3, abstraction 2 [abstractness1, abstraction 1], associations 1, impression 1, eyes 1, actions 1, intellect 1, to see $1-42$ (21\%), f. 19 (9.5\%), m. 23 (11.5\%);

\section{3. Associates that reflect a state of utmost elation and enthusiasm during the creative} process: inspiration $-\mathrm{m} .1(0.5 \%)$;

2) Associates that are connected with creative activity: 51 (25.5\%), f. 25 (12.5\%), m. 26 (13\%). This cluster includes semantic groups 2.1-2.4:

2. 1. Associates that are connected with the end product of creative activity (mainly in art): creative work 8 , creativity 4, paintings 6 [painting 5, paintings 1], art 3, books 2, something made up 2 [something made up 1, to make up 1], sketch 1 , drawing 1 , anime 1 , architecture 1 , unicorn 1 , image 1 , history 1 , course paper $\mathbf{1}$, cartoons 1 , non-existent object $\mathbf{1}$, ode 1 , poetics 1 , silhouette 1 , fairy tale 1 , creation 1 , poems 1 , finish 1 , fantasy $1-43$ (21.5\%), f. 21 (10.5\%), m. 22 (11\%);

2. 2. Associates that actualise precedent texts: SpongeBob 2 (cartoon "SpongeBob SquarePants"), "The Imaginarium of Doctor Parnassus"1 (the eponymous science fiction film), Flesh 1 (the movie "Flesh; Andy Warhol's Flesh") - 4 (2 \%), f. 2 (1\%), m. 2 (1\%);

2. 3. Associates that are proper names: Tolkien 1, Pegasus $1-2$ (1 \%), f. 1 (0.5\%), m. $1(0.5 \%)$;

2. 4. Associates that refer to a profession: artist - 2 (1\%), f. 1 (0.5\%), m. 1 (0.5\%);

3) Associates that describe the outside world (natural phenomena, plants, animals, objects, etc.): 22 (11\%), f. 13 (6.5\%), m. 9 (4.5\%): associates - nature (everything that was not created by a human being) - rainbow 4, world 2, sky 2, clouds 2 [clouds 1, small cloud 1], granite 1 , stars 1 , the globe 1 , whale 1 , landscape 1 , field 1 , reality 1 , hill 1 , particle 1 19 (9.5\%), f. 12 (6\%), m. 7 (3.5\%); associates - objects (everything that was created by a human being): balloons 1 , spade 1 , light bulb $1-3(1.5 \%)$, f. $1(0.5 \%), \mathrm{m} .2(1 \%)$. This is a numerous cluster, which testifies to the fact that abstract things are understood with the help of concrete things;

4) Evaluative associates: perfection 1, uniqueness 1 - 2 (1 \%), f. 1 (0.5 \%), m. 1 (0.5 \%);

5) Age-related associates: child - f. 4 (2\%). This is a small cluster, but female respondents tend to associate imagination with children;

6) Associates that reflect the "innermost circle": home 2, family $1-3(1.5 \%)$, f. 1 (0.5\%), m. 2 (1\%);

7) Associates related to colours: colour 3 [colours 2, colour 1] - f. 3 (1.5\%);

8) Associates related to science: mathematics - m. 1 (0.5\%); 
9) Emotive associates: joy - f. 1 (0.5\%);

10) Theological associates: mysticism - m. 1 (0.5\%);

11) Associates that reflect a low moral standard (sexual promiscuity): lechery - m. 1 (0.5\%);

12) Associates in the form of a fixed expression: crisis 1, unrestrained $1-\mathrm{m} .2$ (1\%). Reactions in the form of a fixed expression: IMAGINATION - crisis 1, seme "there's an expression 'crisis of imagination' ", IMAGINATION - unrestrained 1, seme "there's an expression 'unrestrained imagination' ", were expressed by female respondents (1\%).

\section{Discussion}

The way the semantic group "outside world" is actualised in linguistic consciousness is described in works by M. V. Pimenova on the concept of "imagination". She emphasizes that "imagination" is a concept of the inner world. Such concepts are complicated, because "in order to describe something invisible or metaphysical, a person does not describe new signs, but uses existing ones. Describing the phenomena of the inner world, a native speaker relates them to characteristics of the outside world. In this way, abstract notions are compared with natural elements, substances, living beings, and objects" [18, p. 30].

The actualisation of such semes of "imagination" as "fantasy" (the first subgroup of the first cluster) and "creative work" is indirectly confirmed in the works by A. N. Doborovich and V. A. Kuzmichova on the concept of "creativity". As a result of a free association test with the stimulus word "creativity" (350 reactions) with native speakers of the English language (aged 18-55), the scholars drew the conclusion that the cognitive layer of the concept "creativity" is mainly represented by psychological associates (mental skills - $23 \%$ ) and those, related to creative activity (35\%). The concepts that form the conceptual sphere "creativity" are such core concepts as "creativity" and "imagination" [19].

Interestingly, out of 200 reactions, we found only one emotive reaction, “joy”, which was expressed by a female respondent, despite the fact that M. S. Komandakova in her work on emotional aspects of the concept "imagination" mentions that this concept is characterized by rather strong emotions and feelings [20]. However, it should be noted, that she used the research method of text corpus analysis rather than a free association test.

The frequency analysis of the free association test with the stimulus word "imagination" helped to reveal the general and specific features of the verbal behaviour of the young respondents. On the one hand, the analysis of the general features of their verbal behaviour showed certain stereotypes in the associations, produced by their linguistic consciousness. On the other hand, it is worth mentioning a rather large number of reactions on the extreme periphery - 58 isolated cases (29\% of the total number of reactions) reflect individual characteristics of the respondents, their personal meanings and experience. This signifies that not all the meanings of the lexeme "imagination" are sufficiently mastered by the young respondents.

The analysis of reactions did not reveal any significant difference between male and female samples. It means that the semantic content of the concept imagination does not depend on gender identification. However, the analysis of peripheral clusters helped to identify clusters that are only characteristic of female respondents: age-related associates (childhood) (2\%), associates related to colour $(1.5 \%)$, emotive associates $(0.5 \%)$, as well as those clusters that are only represented by male isolated cases: associates related to science $(0.5 \%)$, theological associates $(0.5 \%)$, associates that reflect a low moral standard $(0.5 \%)$.

\section{Conclusion}

The experiment demonstrated that the psycholinguistic features of imagination as a notion that belongs to the inner world and as a component of the ludic competence were reflected in everyday linguistic consciousness as three core (more than $10 \%$ ) semantic clusters: (a) associates that reflect psychological processes and states (54.5\%); (b) associates that are connected with creative activity (25.5\%); (c) associates that describe the outside world (11\%). Imagination is mostly represented by lexemes with abstract semantics. The "outside world" cluster is rather numerous and 
diverse in its range of reactions. In all likelihood that is because the relationship between the word and an image is rather ambiguous.

The semantic content of the word "imagination" does not depend on gender identification. Both male and female respondents tended to evaluate this stimulus as something positive.

The data, obtained in the course of the experiment, confirm that the psycholinguistic experiment and the method of free association test in particular can be extensively applied beyond linguistics and prove to be rather effective, e. g., for coaching sessions, aimed at comprehending abstract notions and words that are semantically undifferentiated.

Thus, the analysis of the results of the psycholinguistic experiment with the stimulus "imagination" allowed us to understand, which of its meanings are actualised in everyday linguistic consciousness, which of them are core meanings, and which are not sufficiently mastered and therefore have to be introduced in the theoretical-methodological part of the coaching.

The peripheral semantic groups, represented by reactions of male or female respondents, testify to the fact that men and women have certain verbal preferences in reaction to the stimulus "imagination". This allows us to consider these gender differences in the learning process.

\section{Acknowledgments}

The authors express deep gratitude and appreciation to Iosif Sternin, professor of Voronezh State University, for valuable advice and recommendation, when mastering the method of describing psycholinguistic meaning. The authors are also profoundly grateful to Heijiro Tsuji, Professor Emeritus of Konan Womens' University, Kobe, Japan, for providing all the necessary materials and genuine interest to our research; also to Rene Proyer, professor of the Martin Luther University, to Willibald Ruch, professor of the University of Zurich, and to Paulette Guitard, associate professor of the University of Ottawa for their valuable support in exploring playfulness.

This research did not receive any specific grant from funding agencies in the public, commercial, or not-for-profit sectors.

\section{References}

[1] Gordiienko-Mytrofanova, I. (2015). Meanings of playfulness in the current linguistic consciousness of native speakers of Russian. Visnyk of the H. S. Skovoroda KNPU. Psychology, 51, 44-53.

[2] Gordiienko-Mytrofanova, I. V., Sauta, S. L. (2016). Playfulness as a peculiar expression of sexual relationships (semantic interpretation of the results of the psycholinguistic experiment). European Humanities Studies: State and Society, 1, $46-62$.

[3] Gordiienko-Mytrofanova, I., Kobzieva, Iu., Sauta, S. (2019). Psycholinguistic Meanings of Playfulness.East European Journal of Psycholinguistics, 6 (1), 19-31. doi: http://doi.org/10.5281/zenodo.3371627

[4] Sternin, I. A., Rudakova, A. V. (2011). Psikholingvisticheskoie znacheniie slova i yego opisaniie. Lambert, 192.

[5] Gordiienko-Mytrofanova, I., Pidchasov, Ye., Sauta, S., Kobzieva, Iu. (2018). The Problem of Sample Representativeness For Conducting Experimental and Broad Psychological Research. Psycholinguistics, 23 (1), 11-46. doi: http://doi.org/10.5281/ zenodo. 1212360

[6] Gordiienko-Mytrofanova, I., Kobzieva, Iu. (2017). Playful Competence: The Access Code to the Inner Resources. Proceedings of the 15th European Congress of Psychology. Amsterdam, 19.

[7] Guitard, P., Ferland, F., Dutil, É. (2005). Toward a Better Understanding of Playfulness in Adults. OTJR: Occupation, Participation and Health, 25 (1), 9-22. doi: http://doi.org/10.1177/153944920502500103

[8] Tsuji, H., Tsuji, H., Yamada, S., Natsuno, Y., Morita, Y., Mukoyama, Y., Hata, K., Fujishima, Y. (1996). Standardization of the Five Factor Personality Questionnaire: Factor structure. International Journal of Psychology, 31, 103-217.

[9] Proyer, R. T. (2017). A new structural model for the study of adult playfulness: Assessment and exploration of an understudied individual differences variable. Personality and Individual Differences, 108, 113-122. doi: http://doi.org/10.1016/ j.paid.2016.12.011

[10] Gordiienko-Mytrofanova, I., Kobzieva, Iu. (2017). Humor as a component of ludic competence. Visnyk of the H. S. Skovoroda KNPU, 57, 40-56. 
[11] Gordiienko-Mytrofanova, I., Kobzieva, I. (2019). Gender- and Role-Specific Differences in the Perception of the Concept "Impishness" (based on the results of a psycholinguistic experiment). Psycholinguistics, 25 (1), 33-48. doi: http://doi.org/ 10.31470/2309-1797-2019-25-1-33-48

[12] Rubinstein, S. L. (2002). Osnovy obshchei psikhologii. Saint-Petersburg: Piter, 720.

[13] Proyer, R. T. (2012). A Psycho-linguistic Study on Adult Playfulness: Its Hierarchical Structure and Theoretical Considerations. Journal of Adult Development, 19 (3), 141-149. doi: http://doi.org/10.1007/s10804-012-9141-7

[14] Popova, Z. D., Sternin, I. A. (2007). Semantiko-Kognitivnyi Analiz Yazyka. Voronezh: Istoki, 250.

[15] Ufimtseva, N. (2009). Image of the world of Russians: the systemic characteristics and the content. Language and Culture, 98-111.

[16] Ananiev, B.G. (2001). O problemakh sovremennogo cheloveko znaniia. Saint-Petersburg: Piter, 265.

[17] Karaulov, Yu., Cherkasova, G., Ufimtseva, N., Sorokin, Yu., Tarasov, Ye. (2002). Russkii Assotsiativnyi Slovar. Vo2. 1. Otreaktsii k stimulu. Moscow: LLC Astrel Publishers; LLC AST Publishers, 992.

[18] Pimenova, M. V. (2004). Dusha i dukh: osobennosti konceptualizacii. Kemerovo: IPK Grafika, 386.

[19] Doborovich, A. N., Kuzmicheva, V. A. (2014). Psycholinguistic insights into structuring the concept of creativity. Nauchnyye Vedomosti. Seriya Gumanitarnyye Nauki, 26 (24 (197)), 46-52.

[20] Komandakova, M. S. (2012). Emotional attributes of concept of imagination in the English picture of the world. Gumanitarnyi Vektor, 4 (32), 146-150. 